\title{
Novel inflammatory markers in patients with psoriasis
}

\author{
Göknur Özaydın Yavuz , İbrahim Halil Yavuz \\ Department Of Dermatology, Van Yuzuncu Yil University, Van, Turkey
}

\begin{abstract}
Psoriasis is an autoimmune, chronic, inflammatory skin disease affecting approximately $1-3 \%$ of the population worldwide. Neutrophil-to-lymphocyte ratio (NLR) and platelet-to-lymphocyte ratio (PLR) are simple and practical methods used as predictive markers in numerous clinical conditions. In this study, we aimed to investigate the relationship between the severity of psoriasis and NLR, PLR, and MPV levels in patients with psoriasis.

The study included 60 patients who were being followed up due to a diagnosis of psoriasis and 30 healthy controls. The NLR was calculated by dividing neutrophil count by lymphocyte count and the PLR was calculated by dividing platelet count by lymphocyte count.

The 90 participants comprised $45(50.0 \%)$ men and $45(50.0 \%)$ women with a mean age of $41.2 \pm 13.4$ years. Mean PASI score was $8.1 \pm 5.2$, mean MPV was $8.8 \pm 0.9 \mathrm{fL}$, mean platelet count was $262.7 \pm 71.310 \mathrm{e} / \mathrm{uL}$, mean leukocyte count was $7.3 \pm 2.010 \mathrm{e} 3 / \mathrm{uL}$, mean NLR was 1.8 \pm 1.1 , mean PLR was $112.9 \pm 45.9$, and mean duration of disease was $9.4 \pm 7.3$ years.

No significant difference was found in the NLR, PLR, and MPV levels between the patients with psoriasis and the controls. Although psoriasis is a common disease in the general population, there is no specific laboratory marker for the determination of disease severity. On the other hand, although the NLR, PLR, and MPV levels, which can be easily determined by a CBC test, were found to be normal in the patients with psoriasis, accumulating evidence suggests that these parameters are promising for this disease.
\end{abstract}

Key Words: Psoriasis, neutrophil, lymphocyte

\section{Introduction}

Psoriasis is an autoimmune, chronic, inflammatory skin disease affecting approximately $1-3 \%$ of the population worldwide. Psoriatic skin lesions are sharply demarcated, erythematous plaques, which are histologically characterized by increased angiogenesis, inflammatory skin infiltrate, and epidermal changes. The pathogenesis of psoriasis is multifactorial and the disease is mostly associated with genetic, environmental, and immunological factors (1).

Neutrophil-to-lymphocyte ratio (NLR) and platelet-to-lymphocyte ratio (PLR) are simple and practical methods used as predictive markers in numerous clinical conditions (2). Recent reports indicate that NLR and PLR are increased in several diseases including diabetes mellitus, ulcerative colitis, cirrhosis, Behçet's disease, acute coronary syndrome, psoriasis (2,3). Mean platelet volume (MPV) is an indicator of platelet activation and function. Increased MPV values have been implicated in several inflammatory diseases and have been shown to be an independent risk factor for acute myocardial infarction (3).
In this study, we aimed to investigate the relationship between the severity of psoriasis and NLR, PLR, and MPV levels in patients with psoriasis.

\section{Materials and Methods}

The study included 60 patients aged over 18 years who were being followed up due to a diagnosis of psoriasis in in- and out-patient clinics at Medical School Dermatology Department and 30 healthy controls. Exclusion criteria were as follows: obesity, active infection, drug use within the last one month, systemic diseases, smoking, and alcohol abuse. Control subjects were selected from among individuals who had no dermatological or systemic diseases and no drug use within the last month, and those who presented to our polyclinic due to cosmetic reasons. Age, gender, family history, duration of disease, and Psoriasis Area Severity Index (PASI) scores were recorded for each patient. The study was conducted in accordance with the Helsinki Declaration and was initiated after an approval was obtained from the local ethics committee (Number: 02, Date: 04.04.2018).

\footnotetext{
*Corresponding Author: Goknur Ozaydin Yavuz, MD, Van Yuzuncu Yil University Faculty of Medicine, Department of Dermatology, 65100, Van/Turkey 
Table 1. Demographic and laboratory parameters of the participants

\begin{tabular}{lccc}
\hline & & Mean \pm SD & Median \\
\hline Gender* & Male & 45.0 & $(50.0)$ \\
& Female & 45.0 & $(50.0)$ \\
Age (years) & & $41.2 \pm 13.4$ & 40.0 \\
PASI & $8.1 \pm 5.2$ & 6.9 \\
Hemoglobin $(\mathrm{g} / \mathrm{dL})$ & $14.6 \pm 1.7$ & 14.6 \\
MPV (fL) & $8.8 \pm .9$ & 8.8 \\
Platelet $(10 \mathrm{e} 3 / \mathrm{uL})$ & $262.7 \pm 71.3$ & 252.5 \\
Neutrophil $(10 \mathrm{e} 3 / \mathrm{uL})$ & $4.0 \pm 1.8$ & 3.7 \\
Lymphocyte $(10 \mathrm{e} 3 / \mathrm{uL})$ & $2.5 \pm .6$ & 2.4 \\
NLR & $1.8 \pm 1.1$ & 1.5 \\
PLR & $112.9 \pm 45.9$ & 103.9 \\
Leukocyte $(10 \mathrm{e} 3 / \mathrm{uL})$ & $7.3 \pm 2.0$ & 7.0 \\
Duration of disease $($ years $)$ & $9.4 \pm 7.3$ & 10.0 \\
Group* & Patient & 60.0 & $(66.7)$ \\
& Control & 30.0 & $(33.3)$ \\
Family History* & No & 47.0 & $(78.3)$ \\
\multicolumn{2}{l}{ Yes } & 13.0 & $(21.7)$ \\
\hline
\end{tabular}

${ }^{*}$ Categorical variables were expressed as $\mathrm{n}$ instead of mean $\pm \mathrm{SD}$ and as \% instead of median. NLR: Neutrophil-tolymphocyte ratio, PLR: Platelet-to-lymphocyte ratio, MPV: Mean platelet volume, SD: Standard deviation

Table 2. Gender-based comparison of demographic and laboratory parameters

\begin{tabular}{|c|c|c|c|c|c|c|c|}
\hline \multirow[b]{4}{*}{ Age (years) } & \multicolumn{6}{|c|}{ Gender } & \multirow{3}{*}{$\mathrm{p}$} \\
\hline & \multicolumn{3}{|c|}{ Male } & \multicolumn{3}{|c|}{ Female } & \\
\hline & Median & Percen & $(25-75)$ & Median & Percentile & $(25-75)$ & \\
\hline & 42.0 & $(32.0-$ & $52.0)$ & 39.0 & $(27.0-$ & $49.0)$ & 0.281 \\
\hline PASI & 5.6 & (3.1- & $12.0)$ & 7.2 & $(5.0-$ & $11.2)$ & 0.271 \\
\hline Hemoglobin $(\mathrm{g} / \mathrm{dL})$ & 16.0 & $(15.2-$ & 16.4) & 13.6 & $(13.1-$ & $14.2)$ & $<0.001$ \\
\hline Neutrophil (10e3/uL) & 3.8 & $(2.9-$ & $4.8)$ & 3.6 & $(2.8-$ & $4.9)$ & 0.945 \\
\hline NLR & 1.5 & $(1.1-$ & 2.2) & 1.5 & $(1.2-$ & 2.1) & 0.529 \\
\hline Leukocyte (10e3/uL) & 6.9 & $(6.1-$ & $8.2)$ & 7.1 & (6.1- & $8.1)$ & 0.806 \\
\hline $\begin{array}{l}\text { Duration of disease } \\
\text { (years) }\end{array}$ & 8.5 & (3.0- & $10.0)$ & 10.0 & $(5.0-$ & 14.0) & 0.416 \\
\hline MPV (fL)* & $8.6 \pm 1.0$ & $(6.8-$ & 10.4) & $9.0 \pm .9$ & (7.0- & 10.9) & 0.027 \\
\hline Platelet $(10 \mathrm{e} 3 / \mathrm{uL})^{*}$ & $240.5 \pm 62.0$ & (118.0- & 409.0) & $285.0 \pm 73.7$ & $(130.0-$ & $412.0)$ & 0.003 \\
\hline $\begin{array}{l}\text { Lymphocyte } \\
(10 \mathrm{e} / \mathrm{uL})^{*}\end{array}$ & $2.5 \pm .6$ & $(1.5-$ & $3.5)$ & $2.4 \pm .7$ & $(1.1-$ & $4.4)$ & 0.597 \\
\hline PLR* & $97.5 \pm 27.5$ & $(47.2-$ & $177.8)$ & $128.3 \pm 55.0$ & $(46.4-$ & $274.5)$ & 0.001 \\
\hline
\end{tabular}

${ }^{a}$ Independent Samples $t$-test, ${ }^{b}$ Mann-Whitney U test, *Data with normal distribution were expressed as mean \pm SD instead of median and as minimum-maximum values instead of percentile values (25-75). NLR: Neutrophil-tolymphocyte ratio, PLR: Platelet-to-lymphocyte ratio, MPV: Mean platelet volume

Venous blood sampling was performed with the patient in the sitting position. A complete blood count $(\mathrm{CBC})$ test was performed to determine leukocyte, erythrocyte, platelet, and hemoglobin, and MPV levels. The NLR was calculated by dividing neutrophil count by lymphocyte count and the PLR was calculated by dividing platelet count by lymphocyte count. An NLR value of $<2$ was accepted as indicating low risk, $2-5$ as moderate risk, and $\geq 5$ as high risk.

Statistical Analysis: Data were analyzed using SPSS 15.0 for Windows (SPSS Inc. Co., Chicago, IL, USA). Normality of distribution was tested

East J Med Volume:24, Number:1, January-March/2019 
Table 3. Comparison of demographic and laboratory parameters between the patients with and without a positive family history

\begin{tabular}{|c|c|c|c|c|c|c|c|c|}
\hline & \multicolumn{6}{|c|}{ Family History } & \multirow{3}{*}{$\mathrm{p}$} \\
\hline & & \multicolumn{3}{|c|}{ No } & \multicolumn{3}{|c|}{ Yes } & \\
\hline & & Median & Percent & ile $(25-75)$ & Median & Percent & $(25-75)$ & \\
\hline \multicolumn{2}{|c|}{ Age (years) } & 42.0 & (31.0- & $53.0)$ & 33.0 & $(30.0-$ & $50.0)$ & $0.679 \mathrm{~b}$ \\
\hline \multicolumn{2}{|c|}{$\begin{array}{l}\text { Neutrophil } \\
(10 \mathrm{e} 3 / \mathrm{uL})\end{array}$} & 3.6 & $(2.9-$ & $4.7)$ & 4.8 & (3.5- & $6.2)$ & $0.151 \mathrm{~b}$ \\
\hline \multicolumn{2}{|l|}{ NLR } & 1.6 & $(1.2-$ & $2.2)$ & 1.7 & $(1.3-$ & $2.2)$ & $0.473 \mathrm{~b}$ \\
\hline \multicolumn{2}{|l|}{ PLR } & 100.1 & $(76.5-$ & 129.6) & 102.4 & $(85.7-$ & 118.1) & $0.823 \mathrm{~b}$ \\
\hline \multicolumn{2}{|c|}{$\begin{array}{l}\text { Leukocyte } \\
(10 \mathrm{e} 3 / \mathrm{uL})\end{array}$} & 6.9 & $(6.3-$ & 7.7) & 7.8 & (5.6- & $9.1)$ & $0.181 \mathrm{~b}$ \\
\hline \multicolumn{2}{|c|}{$\begin{array}{l}\text { Duration of disease } \\
\text { (years) }\end{array}$} & 7.0 & $(3.0-$ & 11.0) & 10.0 & $(10.0-$ & 12.0) & $0.120 \mathrm{~b}$ \\
\hline \multicolumn{2}{|c|}{ PASI* } & $7.9 \pm 4.8$ & $(2.3-$ & $23.0)$ & $9.0 \pm 6.7$ & $(1.9-$ & 23.0) & $0.498 \mathrm{a}$ \\
\hline \multicolumn{2}{|c|}{$\begin{array}{l}\text { Hemoglobin } \\
(\mathrm{g} / \mathrm{dL})^{*}\end{array}$} & $14.5 \pm 1.8$ & $(9.7-$ & 17.7) & $14.3 \pm 1.9$ & (11.3- & $17.0)$ & $0.650 \mathrm{a}$ \\
\hline \multicolumn{2}{|c|}{$\mathrm{MPV}(\mathrm{fL}) *$} & $8.9 \pm 1.0$ & $(7.0-$ & 10.9) & $8.8 \pm 1.0$ & $(6.8-$ & 10.3) & $0.799 \mathrm{a}$ \\
\hline \multicolumn{2}{|c|}{ Platelet $(10 \mathrm{e} 3 / \mathrm{uL}) *$} & $259.7 \pm 77.9$ & (118.0- & 412.0) & $261.2 \pm 56.2$ & $(147.0-$ & $331.0)$ & $0.950 \mathrm{a}$ \\
\hline \multirow{2}{*}{\multicolumn{2}{|c|}{$\begin{array}{l}\text { Lymphocyte } \\
(10 \mathrm{e} 3 / \mathrm{uL})^{*}\end{array}$}} & $2.4 \pm .6$ & $(1.3-$ & $3.5)$ & $2.5 \pm .8$ & $(1.1-$ & $4.2)$ & $0.627 \mathrm{a}$ \\
\hline & & $\mathrm{n}$ & & $\%$ & $\mathrm{n}$ & & 0 & \\
\hline \multirow[t]{2}{*}{ Gender } & Male & 23.0 & & (76.7) & 7.0 & & $.3)$ & $0.754 \mathrm{c}$ \\
\hline & Female & 24.0 & & (80.0) & 6.0 & & .0) & \\
\hline
\end{tabular}

${ }^{a}$ Independent Samples t-test, bMann-Whitney $U$ test, cChi-square test, $*$ Data with normal distribution were expressed as mean $\pm S D$ instead of median and as minimum-maximum values instead of percentile values (25-75). NLR: Neutrophil-to-lymphocyte ratio, PLR: Platelet-to-lymphocyte ratio, MPV: Mean platelet volume, SD: Standard Deviation, Min.: Minimum, Max.: Maximum

Table 3. Comparison of demographic and laboratory parameters between the patient and control groups

\begin{tabular}{|c|c|c|c|c|c|c|c|}
\hline \multirow[b]{4}{*}{ Age (years) } & \multicolumn{6}{|c|}{ Group } & \multirow{3}{*}{$\mathrm{p}$} \\
\hline & \multicolumn{3}{|c|}{ Patient } & \multicolumn{3}{|c|}{ Control } & \\
\hline & \multirow{2}{*}{$\frac{\text { Median }}{40.5}$} & \multicolumn{2}{|c|}{ Percentile (25-75) } & \multirow{2}{*}{$\frac{\text { Median }}{40.0}$} & \multicolumn{2}{|c|}{ Percentile $(25-75)$} & \\
\hline & & $(30.5-$ & $51.0)$ & & $(35.0-$ & $50.0)$ & $0.436 \mathrm{~b}$ \\
\hline $\mathrm{MPV}(\mathrm{fL})$ & 8.9 & $(8.3-$ & $9.6)$ & 8.8 & $(8.1-$ & $9.3)$ & $0.800 \mathrm{~b}$ \\
\hline $\begin{array}{l}\text { Neutrophil } \\
(10 \mathrm{e} 3 / \mathrm{uL})\end{array}$ & 3.8 & $(2.9-$ & 4.9) & 3.2 & $(2.5-$ & $4.5)$ & $0.189 \mathrm{~b}$ \\
\hline $\begin{array}{l}\text { Lymphocyte } \\
(10 \mathrm{e} 3 / \mathrm{uL})\end{array}$ & 2.4 & $(2.1-$ & 2.9) & 2.4 & $(2.1-$ & 2.6) & $0.928 \mathrm{~b}$ \\
\hline NLR & 1.6 & $(1.3-$ & 2.2) & 1.4 & $(1.1-$ & 1.7) & $0.056 \mathrm{~b}$ \\
\hline PLR & 101.3 & (79.4- & 127.4) & 108.4 & (81.9- & 145.6) & $0.716 \mathrm{~b}$ \\
\hline $\begin{array}{l}\text { Leukocyte } \\
(10 \mathrm{e} 3 / \mathrm{uL})\end{array}$ & 7.0 & $(6.3-$ & $7.8)$ & 6.9 & $(5.9-$ & $8.6)$ & $0.817 \mathrm{~b}$ \\
\hline $\begin{array}{l}\text { Hemoglobin } \\
(\mathrm{g} / \mathrm{dL})^{*}\end{array}$ & $14.5 \pm 1.8$ & $(9.7-$ & 17.7) & $14.7 \pm 1.2$ & $(12.9-$ & 16.8) & $0.503 \mathrm{a}$ \\
\hline $\begin{array}{l}\text { Platelet } \\
(10 \mathrm{e} 3 / \mathrm{uL})^{*}\end{array}$ & $260.0 \pm 73.3$ & (118.0- & $412.0)$ & $268.2 \pm 68.1$ & (161.0- & $394.0)$ & $0.611 \mathrm{a}$ \\
\hline
\end{tabular}

${ }^{a}$ Independent Samples $t$-test, ${ }^{b}$ Mann-Whitney $U$ test, ${ }^{\mathrm{c} C h i-s q u a r e ~ t e s t, ~} *$ Data with normal distribution were expressed as mean $\pm S D$ instead of median and as minimum-maximum values instead of percentile values (25-75). NLR: Neutrophil-to-lymphocyte ratio, PLR: Platelet-to-lymphocyte ratio, MPV: Mean platelet volume 
Table 5. Correlations between the PASI score, NLR, PLR and demographic and laboratory parameters

\begin{tabular}{lllllll}
\hline & PASI & & NLR & \multicolumn{3}{l}{ PLR } \\
\hline & $\mathrm{r}$ & $\mathrm{P}$ & $\mathrm{r}$ & $\mathrm{p}$ & $\mathrm{r}$ & $\mathrm{p}$ \\
\hline PASI & 1.000 & $\cdot$ & 0.166 & 0.205 & 0.092 & 0.486 \\
Age (years) & 0.189 & 0.147 & 0.125 & 0.241 & -0.027 & 0.802 \\
Hemoglobin (g/dL) & -0.168 & 0.201 & -0.031 & 0.773 & -0.309 & 0.003 \\
MPV (fL) & 0.072 & 0.587 & 0.244 & 0.021 & -0.214 & 0.043 \\
Platelet (10e3/uL) & -0.089 & 0.500 & 0.076 & 0.475 & 0.732 & $<0.001$ \\
Neutrophil (10e3/uL) & 0.088 & 0.506 & 0.706 & $<0.001$ & -0.096 & 0.366 \\
Lymphocyte (10e3/uL) & -0.193 & 0.140 & -0.305 & 0.003 & -0.543 & $<0.001$ \\
Leukocyte (10e3/uL) & -0.049 & 0.709 & 0.313 & 0.003 & -0.183 & 0.085 \\
Duration of disease (years) & 0.214 & 0.100 & 0.215 & 0.099 & -0.031 & 0.813 \\
\hline
\end{tabular}

Spearman's Correlation Coefficient, NLR: Neutrophil-to-lymphocyte ratio, PLR: Platelet-to-lymphocyte ratio, MPV: Mean platelet volume

using histogram plots and the KolmogorovSmirnov test. Descriptive statistics were expressed as mean, standard deviation (SD), median, and $25^{\text {th }}-75^{\text {th }}$ percentile values. Data with normal distribution were compared using Independent Samples t-test and data with nonnormal distribution were compared using the Two-Sample Mann-Whitney U test. Quantitative variables were compared using Spearman's Correlation Coefficient and categorical variables were compared using Pearson's Chi-Square test. A p value of $<0.05$ was considered significant.

\section{Results}

The 90 participants comprised $45(50.0 \%)$ men and $45(50.0 \%)$ women with a mean age of 41.2 \pm 13.4 years. Mean PASI score was 8.1 \pm 5.2 , mean hemoglobin count was $14.6 \pm 1.7 \mathrm{~g} / \mathrm{dL}$, mean MPV was $8.8 \pm 0.9 \mathrm{fL}$, mean platelet count was $262.7 \pm 71.310 \mathrm{e} 3 / \mathrm{uL}$, mean neutrophil count was $4.0 \pm 1.810 \mathrm{e} 3 / \mathrm{uL}$, mean lymphocyte count was $2.5 \pm .610 \mathrm{e} 3 / \mathrm{uL}$, mean leukocyte count was $7.3 \pm 2.010 \mathrm{e} 3 / \mathrm{uL}$, mean NLR was $1.8 \pm 1.1$, mean PLR was $112.9 \pm 45.9$, and mean duration of disease was $9.4 \pm 7.3$ years. A positive family history was found in $13.0 \%$ of the patients.

A gender-based analysis revealed that mean hemoglobin count was significantly higher in men (16.0; range, 15.2-16.4 g/dL) than in women (13.6; range, $13.1-14.2 \mathrm{~g} / \mathrm{dL}) \quad(p<0.001)$, MPV was

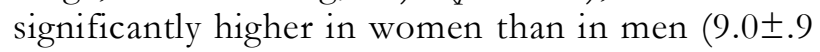
vs. $8.6 \pm 1.0 \mathrm{fL})(p=0.027)$, mean platelet count was significantly higher in women than in men $(285.0 \pm 73.7$ vs. $240.5 \pm 62.010 \mathrm{e} 3 / \mathrm{uL}) \quad(p=0.003)$, mean PLR was higher in women than in men (128.3 \pm 55.0 vs. $97.5 \pm 27.5)(p=0.001)$, whereas no significant difference was found in the other demographic and laboratory parameters between the genders $(p>0.05)$.

No significant difference was found in the demographic and laboratory parameters between the patients with and without a positive family history $(p>0.05)$ (Table 3).

No significant difference was found in the demographic and laboratory parameters between the patient and control groups $(p>0.05)$ (Table 4).

The PASI scores established no significant correlation with any demographic or laboratory parameter $(p>0.05)$. However, a weak positive correlation was found between NLR and MPV $(\mathrm{r}=0.244 ; p=0.021)$, a strong positive correlation was found between NLR and neutrophil count $(\mathrm{r}=0.706 ; \quad p<0.001), \quad \mathrm{a}$ moderate negative correlation was found between NLR and lymphocyte count $(\mathrm{r}=-0.305 ; p=0.003)$, a moderate positive correlation was found between NLR and leukocyte count ( $\mathrm{r}=0.313 ; p=0.003)$, a moderate negative correlation was found between PLR and hemoglobin count $(\mathrm{r}=-0.309 ; p=0.003)$, a weak negative correlation was found between PLR and MPV ( $\mathrm{r}=-0.214 ; p=0.043)$, a strong positive correlation was found between PLR and platelet count $(\mathrm{r}=0.732 ; p<0.001)$, and a moderate negative correlation was found between PLR and lymphocyte count $(\mathrm{r}=-0.543 ; p<0.001)$ (Table 5).

\section{Discussion}

Psoriasis is a chronic, multisystem, inflammatory disease with predominantly skin and joint involvement. Psoriasis is characterized by a network activation including numerous immune factors such as T-cells, dendritic cells, neutrophils, monocytes, and secreted cytokines (4). Literature

East J Med Volume:24, Number:1, January-March/2019 
indicates that there is still no universal laboratory marker of psoriasis activity. However, although adhesion molecules and cytokines have been shown to be useful markers in the determination of psoriasis activity, these two methods are highly costly and require experienced laboratory staff $(5,6)$. Therefore, there is need for more practical and reliable methods for the determination of psoriasis activity. NLR and PLR are easilycalculable, routinely-used, low-cost markers of systemic inflammation (6).

Literature reviews indicate that there are a limited number of studies reporting on the relationship between psoriasis and NLR, PLR. Polat et al. evaluated NLR and PLR in 92 individuals including 46 patients with chronic plaque psoriasis and 46 healthy controls and reported that both NLR and PLR were significantly higher in the patients compared to the controls. The authors concluded that NLR and PLR are highly important parameters in the determination of disease activity and in the follow-up of patients with psoriasis (5). However, in contrast to the study by Polat et al., the present study had a larger patient population and had a prospective design. Moreover, in our study, no significant difference was found in the PLR values between the patient and control groups, although a significant difference was found in terms of genders. Minakawa et al. evaluated C-reactive protein (CRP) and NLR levels in patients with psoriasis and suggested that these two parameters are highly important particularly in the determination of the severity and early diagnosis of psoriasis. In our study, no evaluation was performed for CRP and no relationship was found between NLR and disease activity. This finding implicates that NLR may not always predict the disease activity. Moreover, in comparison to the study by Minakawa et al., our study also evaluated PLR and MPV values (7).

Unal et al. evaluated PLR, NLR, and CRP values in 320 patients with psoriasis and 200 healthy controls and reported that the increase in these parameters may be closely associated with the development of psoriasis. Although the study had a retrospective design, it had a larger patient population compared to our study (8).

Erek et al. evaluated NLR in 88 individuals including 39 patients with psoriasis and 49 healthy controls and reported that the NLR levels were significantly higher in the patients compared to the controls and the narrow-band ultraviolet $\mathrm{B}$ (NB-UVB) phototherapy treatment had no effect on NLR. In contrast, although we did not evaluate pre- and post-treatment values, our study had a larger patient population and also evaluated MPV and PLR in our patients (9).

Cemil et al. evaluated 42 patients with psoriasis and suggested that both NLR and PLR can be effectively used in patients receiving biologic treatment of psoriasis (4). Similarly, Cerman et al. evaluated NLR and CRP values in patients receiving systemic treatment of psoriasis and reported that CRP can be a useful marker in the determination of disease severity and in the prediction of therapeutic response (10). In our study, although we obtained similar findings to the study by Cemil et al., no evaluation was performed for CRP.

Recent reports indicate that the importance of platelets in inflammatory disorders has remarkably improved, mainly due to the recent advancements in the quantification of laboratory markers of platelet function. MPV has recently emerged as a reliable marker of platelet function and thrombopoiesis (11). On the other hand, MPV is accepted as an independent risk factor for numerous diseases including cardiovascular diseases, Behçet's disease, Venous thromboembolism, systemic lupus erythematosus, rheumatoid arthritis, and inflammatory bowel disease (11-13). Canpolat et al. evaluated MPV in 106 patients with psoriasis and 95 healthy controls and reported that MPV was higher in the patients compared to the controls and also noted that MPV is a key parameter for disease activity (3). In a similar study, Kilic et al. evaluated MPV in 247 individuals including 116 patients with psoriatic arthritis, 41 patients with psoriasis vulgaris, and 90 healthy controls and reported that MPV was higher in the patients with psoriatic arthritis and patients with psoriasis vulgaris compared to the controls. The authors noted that MPV can be a novel marker of psoriasis (14). Kim et al. evaluated 176 patients with psoriasis and 101 healthy controls and reported that MPV was higher in the patients compared to the controls, particularly in those with a high PASI score. The authors suggested that MPV is typically increased in patients with psoriasis since psoriasis is a systemic inflammatory disease (15). In our study, MPV established no significant difference between the patient and control groups. This finding, contrary to the findings of previous studies, implicates that MPV may not be a significant parameter in patients with psoriasis.

Our study was limited since it was single-centered study, had a relatively small patient population, 
and did not evaluate pre- and post-treatment values of the parameters.

In conclusion, no significant difference was found in the NLR, PLR, and MPV levels between the patients with psoriasis and the controls. However, the PLR levels were significantly higher in women than in men. Although psoriasis is a common disease in the general population, there is no specific laboratory marker for the determination of disease severity. On the other hand, although the NLR, PLR, and MPV levels, which can be easily determined by a CBC test, were found to be normal in the patients with psoriasis, accumulating evidence suggests that these parameters are promising for this disease. Further prospective, multi-centered studies are needed to substantiate our findings.

\section{References}

1. Batycka-Baran A, Maj J, Wolf R, Szepietowski JC. The new insight into the role of antimicrobial proteins-alarmins in the immunopathogenesis of psoriasis. J Immunol Res 2014; 2014: 628289.

2. Bakshi SS. Neutrophil-Lymphocyte and Thrombocyte-Lymphocyte Ratio for the Effusion Viscosity in Otitis Media. J Craniofac Surg 2018; 29: e98.

3. Canpolat F, Akpinar H, Eskioğlu F. Mean thrombocyte volume in and psoriatic arthritis. Clin Rheumatol 2010; 29: 325-328.

4. Cemil B, Ataş H. Psoriasis hastalarında biyolojik tedavinin sistemik inflamatuvar belirteçler ve platelet üzerine etkisi. Dicle Medical Journal 2016; 43: 477-483.

5. Polat M, Bugdayci G, Kaya H, Oğuzman H. Evaluation of neutrophil-to-lymphocyte ratio and thrombocyte-to-lymphocyte ratio in Turkish patients with chronic plaque. Acta Dermatovenerol Alp Pannonica Adriat 2017; 26: 97-100.

6. Fan W, Zhang Y, Wang Y, Yao X, Yang J, Li J. Neutrophil-to-lymphocyte and thrombocyte-to-lymphocyte ratios as predictors of survival and metastasis for recurrent hepatocellular carcinoma after transarterial chemoembolization. PLoS One 2015; 10: e0119312.

7. Minakawa S, Kaneko T, Matsuzaki Y, Yamada M, Kayaba H, Sawamura D. Area and Severity Index is closely related to serum C-reactive protein level and neutrophil to lymphocyte ratio in Japanese patients. J Dermatol 2017; 44: e236-e237.

8. Ünal M, Küçük A, Ünal GÜ, et al. Mean platelet volume, neutrophil to lyphocyte ratio and platelet to lymphocyte ratio in psoriasis. Türkderm 2015; 49: 112-116.

9. Erek Toprak A, Ozlu E, Uzuncakmak TK, Yalcinkaya E, Sogut S, Karadag AS Neutrophil/Lymphocyte Ratio, Serum Endocan, and Nesfatin-1 Levels in Patients with Vulgaris Undergoing Phototherapy Treatment. Med Sci Monit 2016; 22: 1232.

10. Çerman A, Karabay A, Altunay. Psöriyazisli Hastalarda Sistemik Tedaviye Verilen Yanıtın C-Reaktif Protein veNötrofifil Lenfosit Oranı ile İlişkisinin Değerlendirilmesi: Ön Çalışma .Turkiye Klinikleri J Dermatol 2016; 26: 71-75.

11. Gasparyan AY, Ayvazyan L, Mikhailidis DP, Kitas GD. Mean platelet volume: a link between thrombosis and inflammation? Curr Pharm Des 2011; 17: 47-58.

12. Chu SG, Becker RC, Berger PB, et al. Mean platelet volume as a predictor of cardiovascular risk: a systematic review and meta-analysis. J Thromb Haemost 2010; 8: 148-156.

13. Kisacik B, Tufan A, Kalyoncu U, et al. Mean platelet volume (MPV) as an inflammatory marker in ankylosing spondylitis and rheumatoid arthritis. Joint Bone Spine 2008; 75: 291-294.

14. Kılıç S, Reşorlu H, Işik S, et al. Association between mean trombosit volume and disease severity in patients with and psoriatic arthritis. Postepy Dermatol Alergol 2017; 34: 126-130.

15. Kim DS, Lee J, Kim SH, Kim SM, Lee MG. Mean platelet volume is elevated in patients with vulgaris. Yonsei Med J 2015; 56: 712-718. 